\title{
Leishmaniasis visceral. Caso clínico pediátrico
}

\author{
Visceral leishmaniasis. Pediatric case report
}

\author{
Dr. Andrés Gomila $(h)^{a}$, Dra. Carolina Vanzo ${ }^{a}$ Dra. Analía Garnero ${ }^{a}$, Dra. Luisina Peruzzo $y$ \\ Dra. Mónica Badalottib
}

\section{RESUMEN}

La leishmaniasis es una enfermedad causada por parásitos obligados intracelulares pertenecientes al género Leishmania y que reconoce tres formas clínicas principales: cutánea, visceral y mucocutánea. Es una patología del grupo delas “enfermedades desatendidas". Es la única enfermedad tropical transmitida a través de vectores que se ha mantenido endémica por décadas en el sur de Europa. La leishmaniasis visceral representa la forma más grave. Se caracteriza por fiebre, pérdida de peso, anemia y hepatoesplenomegalia. Su período de incubación oscila entre 2 semanas y 18 meses.

La leishmaniasis se considera una enfermedad reemergente a nivel mundial. Algunos de los factores que favorecen esta situación son los cambios en las condiciones climáticas, migraciones y urbanizaciones deficitarias en saneamiento ambiental.

Se presenta el caso de un niño europeo que estaba vacacionando en Córdoba y fue derivado a nuestro Hospital por fiebre y pancitopenia, lo que generó un abordaje multidisciplinario con resolución clínica favorable.

Palabras clave: leishmaniasis visceral, esplenomegalia.

\begin{abstract}
Leishmaniasis is a disease caused by obligate intracellular parasites of the genus Leishmania. There are three main clinical forms of leishmaniasis: cutaneous, visceral and mucocutaneous. It belongs to the diverse group of the tropical "neglected diseases" and is the only tropical vector-borne disease that has remained endemic to southern Europe for decades. Visceral leishmaniasis represents the most serious clinical syndrome. It is characterized by fever, weight loss, anemia and enlargement of the spleen and liver. Incubation period is usually from 2 weeks to 18 months.

Leishmaniasis is considered a worldwide reemerging disease. Some of the factors that favor this situation are the changes in the climatic conditions, migrations and urbanizations deficient in environmental sanitation.

We report an interesting case of an European child who was spending holidays in Cordoba and presented to our hospital with fever and pancytopenia, motivating a multidisciplinary approach with favorable clinical outcome.

Key words: visceral leishmaniasis, splenomegaly.
\end{abstract}

a. Servicio de Clínica Pediátrica, División Infectología.

b. Servicio de Clínica Pediátrica, División Internación.

Hospital de Niños delaSantísima Trinidad, Córdoba, Argentina.

Correspondencia:

Dr. Andrés Gomila (h): drgomila@gmail.com

Financiamiento: Ninguno.

Conflicto de intereses: Ninguno que declarar.

Recibido: $12-12-2016$

Aceptado: 16-2-2017 http:/ / dx.doi.org/10.5546/ aap.2017.e251

Cómo citar: Gomila A, Vanzo C, Garnero A, et al. Leishmaniasis visceral. Caso clínico pediátrico. Arch Argent Pediatr 2017;115(4):e251-e254.

\section{INTRODUCCIÓN}

La leishmaniasis es una enfermedad causada por parásitos obligados intracelulares pertenecientes al género Leishmania, transmitida al hombre a través de la picadura de insectos flebótomos. ${ }^{1}$ Se reconocen tres formas clínicas de presentación: leishmaniasis visceral (LV, conocida como kala-azar, es la forma más grave), cutánea y mucocutánea. ${ }^{2}$

Se reportan, aproximadamente, 500000 casos anuales de LV en el mundo y alrededor de 50000 muertes por esta enfermedad; ${ }^{1}$ los niños son los más afectados.

La LV es altamente endémica en el subcontinente indio y África oriental, donde la transmisión es, sobre todo, interhumana y es causada por Leishmania donovani.

La LV debida a Leishmania infantum se extiende desde la cuenca del Mediterráneo hasta China y produce enfermedad en los caninos; estos son el principal reservorio y de quienes contrae la enfermedad el hombre. En América, la especie descrita como Leishmania chagasi es indiferenciable de Leishmania infantum por técnicas inmunoenzimáticas. ${ }^{3}$

En 2014, más del 90\% de los nuevos casos notificados a la Organización Mundial de la Salud (OMS) se produjeron en 6 países: Brasil, Etiopía, India, Somalia, Sudán y Sudán del Sur. ${ }^{2}$

Múltiples factores favorecen la reemergencia de esta patología a nivel mundial: los cambios climáticos y deforestaciones, que ocasionan una mayor exposición de las personas a los vectores, migraciones desorganizadas, urbanizaciones deficitarias en saneamiento ambiental y tendencias regionales a la tropicalización.

Presentamos un caso clínico que generó un dilema diagnóstico y que motivó un interesante debate interdisciplinario con una resolución clínica favorable. 


\section{CASO CLÍNICO}

Paciente de 17 meses de vida, oriundo de Alemania, previamente sano, que consultó el 01/01/2015 en el Hospital Regional de Santa Rosa de Calamuchita, Córdoba, por fiebre de alrededor de 10 días de evolución, acompañada de decaimiento general, hiporexia y dolor abdominal.

El niño había viajado desde su ciudad de residencia, Frankfurt, Alemania, a Barcelona, España, el 20/12/2014. Dos días más tarde, comenzó con $38^{\circ} \mathrm{C}$ de fiebre; consultó y recibió tratamiento sintomático. El 26/12/2014, al persistir febril, dos registros diarios de $39^{\circ} \mathrm{C}$ $40{ }^{\circ} \mathrm{C}$, consultaron en un centro de salud pediátrico referente de la ciudad de Barcelona, donde se le realizó una radiografía de tórax, que fue normal, y, con un diagnóstico de cuadro infeccioso de la vía aérea superior, fue medicado con amoxicilina y se lo autorizó a viajar el día siguiente hacia Argentina.

Al persistir febril, el 01/01/2015, ya en Santa Rosa de Calamuchita, provincia de Córdoba, consultaron en el hospital local, donde se documentó pancitopenia: $2700 / \mathrm{mm}^{3}$ glóbulos blancos (neutrófilos: 837), hemoglobina de $6 \mathrm{~g} / \mathrm{dl}$ y $48000 / \mathrm{mm}^{3}$ plaquetas, motivo por el cual fue derivado a nuestra Institución.

El paciente había nacido en España y vivía en Frankfurt desde los 3 meses de vida. Desde entonces, permaneció en Alemania, excepto por una viaje a Barcelona de 7 días en agosto de 2014. Madre española y padre argentino. Dos hermanos mayores de 5 y 3 años, ambos sanos.

Inmunizaciones completas para su edad y acordes al calendario alemán. Sin contactos con personas enfermas o mascotas. Al momento del examen físico en nuestra Institución, el paciente se encontraba febril, normohidratado, con regular estado general, con palidez generalizada. Se auscultaba un soplo sistólico 2 / 6 y se palpaba hepatoesplenomegalia.

Ante la sospecha de enfermedad hematológica, se internó en la Sala de Oncohematología.

Nuevo control hematológico: $3200 / \mathrm{mm}^{3}$ glóbulos blancos, hemoglobina de $6,4 \mathrm{~g} / \mathrm{dl}$, $20000 / \mathrm{mm}^{3}$ plaquetas, $0,5 \%$ de reticulocitos $\mathrm{y}$ proteína $C$ reactiva (PCR) de $138 \mathrm{mg} / \mathrm{L}$.

Ecografía abdominal: hígado homogéneo aumentado de tamaño sin dilatación del sistema intra- y extrahepático. Bazo aumentado de tamaño, medición de $108 \mathrm{~mm}$, vesícula biliar con edema perivesicular. Moderada cantidad de líquido libre en la cavidad peritoneal.
Se realizaron serologías virales: citomegalovirus, virus de Epstein-Barr, parvovirus B19 y virus de la inmunodeficiencia humana (VIH); se policultivó y comenzó antibioticoterapia empírica con piperacilinatazobactam. Las serologías y los cultivos fueron todos negativos.

Al día siguiente, se realizó una punción de médula ósea. En el frotis, no se identificaron blastos ni actividad macrofágica, pero se observaron organismos intra- y extracelulares (Figura 1). Se confirmó la presencia de parásitos intra- y extracelulares compatibles con Leishmania spp. El cultivo de médula ósea fue negativo. Comenzó un tratamiento con $5 \mathrm{mg} /$ $\mathrm{kg} /$ día de anfotericina B liposomal el 05/01/15.

Al tercer día de tratamiento, febril y con leve dificultad respiratoria, se decidió su paso a la Unidad de Cuidados Intermedios para mejor monitoreo y control. La evolución clínica fue favorable, con desaparición de las manifestaciones clínicas, resolución de las alteraciones hematológicas y marcado descenso de los reactantes de fase aguda (Figura 2). El paciente persistió febril hasta el $6^{\circ}$ día de tratamiento. Completó 8 días en total de anfotericina en su formulación lipídica.

\section{DISCUSIÓN}

Leishmania es un parásito flagelado tisular y hemático transmitido por diferentes géneros y especies de insectos flebótomos conocidos popularmente como jején o mosca de arena.

Figura 1. Frotis de médula ósea

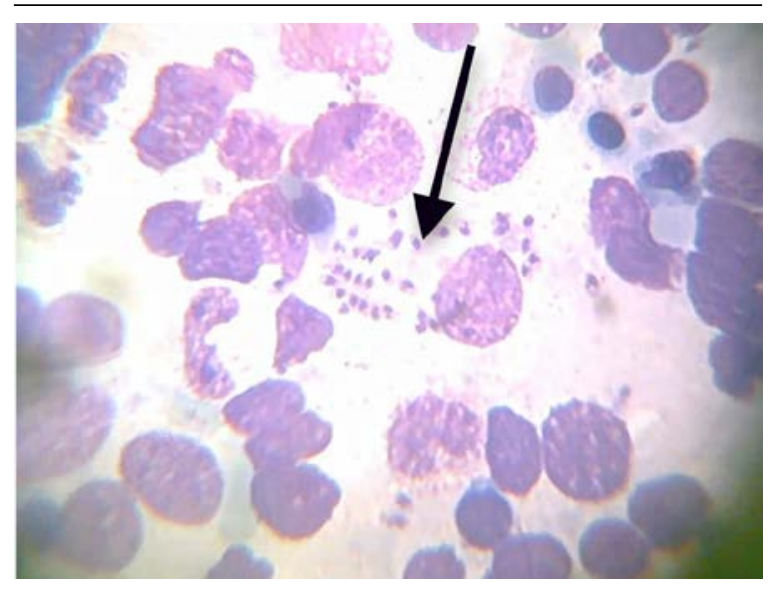

Amastigotes intra- y extracelulares (flecha) 
Los vectores varían según la especie de Leishmania. En América, la leishmaniasis es transmitida por flébotomos del género Lutzomya, mientras que, en Europa, el agente transmisor pertenece al género Phlebotomus. ${ }^{4}$

Se describen tres grandes síndromes clínicos: LV o kala-azar, cutáneo y mucocutáneo. En todos, las células parasitadas son los macrófagos. El tipo de presentación clínica depende de varios factores, entre ellos: la especie de Leishmania, el tropismo y la virulencia del parásito y la susceptibilidad del huésped, la cual estaría genéticamente determinada. La inmunidad mediada por células es el principal mecanismo inmunológico implicado en el control de esta enfermedad. De ahí que la LV en pacientes $\mathrm{VIH}(+)$ sea mucho más frecuente, con mayor tasas de recaídas y menor respuesta al tratamiento, particularmente en aquellos con recuentos muy bajos de linfocitos CD4. ${ }^{5}$ Una infección por VIH incrementa el riesgo de desarrollar LV entre 100 y 2320 veces en aquellos que habitan en áreas endémicas. En Europa, hasta un $70 \%$ de los casos de LV en adultos están asociados con infección por VIH. ${ }^{6}$

La LV es endémica en 70 países y, sin tratamiento, alcanza una mortalidad del $90 \% .^{7}$ Aproximadamente, el $90 \%$ de las LV notificadas en nuestro continente ocurren en Brasil. ${ }^{5,8}$

Si bien se trata de un caso importado, este representa el primer reporte de LV en la provincia de Córdoba. ${ }^{9}$ En el año 2014, se había notificado en Córdoba el primer caso de leishmaniasis cutánea autóctono. ${ }^{10}$
La LV en Argentina es de notificación obligatoria a través del Sistema Nacional de Vigilancia de la Salud. El primer caso autóctono de LV humana notificado en nuestro país ocurrió en el año 2006 en Posadas, Misiones, ciudad donde se encontraba tanto el vector, Lutzomyia longipalpis, como el reservorio, la leishmaniasis canina. ${ }^{11}$ En el período comprendido entre mayo de 2006 y julio de 2012, se notificaron 103 casos de LV en Argentina, en las siguientes provincias: Misiones (la más afectada, con 80 casos), Corrientes, Salta y Santiago del Estero. El grupo etario con mayor afectación correspondió al de niños de entre 0 y 15 años (46\%), y la tasa de letalidad con tratamiento fue del $11 \% .{ }^{12}$

Aunque muchos todavía la consideran una enfermedad tropical, la LV es endémica en 9 países del oeste y sudeste de Europa, entre los que se incluye España. ${ }^{13}$ Otros países del norte europeo, como Alemania, reportan, con frecuencia, casos importados de LV en personas que han vacacionado en países europeos mediterráneos. ${ }^{14}$ Se reportó un caso aislado de LV en un niño alemán que no ingresó nunca en una zona endémica. ${ }^{15}$

En el caso particular de nuestro paciente, se cree que, durante su paso por España, contrajo la enfermedad y que, debido a su extenso y variable período de incubación, comenzó con las manifestaciones clínicas meses después, días previos a su llegada a nuestro país. Afortunadamente, y a pesar de no estar familiarizados con la enfermedad, el diagnóstico se realizó en las primeras 48 horas desde su

\section{PCR}

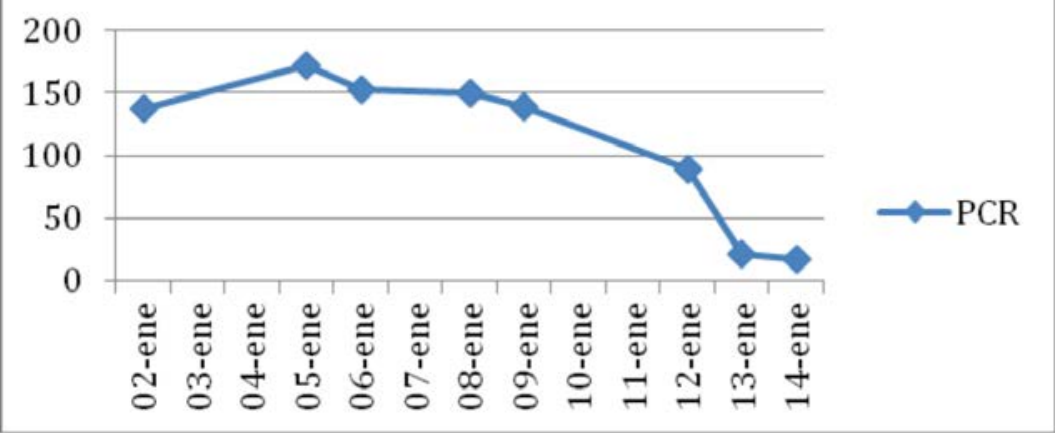

PCR: proteína C reactiva. 
ingreso, lo cual permitió comenzar el tratamiento adecuado en forma temprana.

El tratamiento utilizado en Argentina está normatizado con el esquema terapéutico sugerido por la OMS. Las drogas utilizadas son los antimoniales pentavalentes y la anfotericina B; esta última es la droga de elección en el continente europeo. ${ }^{1}$ Nuestro paciente recibió anfotericina B liposomal, con una excelente respuesta terapéutica, clínica, bioquímica y hematológica.

La leishmaniasis forma parte de aquellas enfermedades consideradas desatendidas. $\mathrm{Su}$ desconocimiento y, particularmente, de su epidemiología puede llevar a una demora diagnóstica con el consiguiente riesgo de vida para el paciente.

\section{REFERENCIAS}

1. Argentina. Ministerio deSalud dela Nación. Enfermedades Infecciosas. leishmaniasis Visceral: Diagnóstico de leishmaniasis Visceral.Guías para el equipo de salud 2010;5. [Acceso: 16 de febrero de 2017]. Disponible en: http:// www.msal.gob.ar/images/stories/bes/graficos / 000000 0798cnt-2012-03-15_leishmaniasis-visceral-guia.pdf.

2. Organización Mundial de la Salud. Leishmaniasis. September 2016. [Acceso: 22 deoctubre de2016]. Disponible en:http: / / www.who.int/mediacentre / factsheets / fs375 / es/.

3. Instituto Nacional de Parasitología. Dr. Mario Fatala Chaben. Leishmaniasis. [Acceso: 22 de octubre de 2016]. Disponible en: http:/ / www.anlis.gov.ar/inp/?page_ id $=316$.

4. Ready PD. Epidemiology of visceral leishmaniasis. Clin Epidemiol 2014;6:147-54.
5. Lindoso JA, Cunha MA, Queiroz IT, et al. LeishmaniasisHIV coinfection: current challenges. HIV AIDS (Auckl) 2016;8:147-56.

6. World Health Organization. Leishmaniasis and HIV coinfection. [Acceso: 22 de octubre de 2016]. Disponible en: http: / / www.who.int/leishmaniasis/burden/hiv_ coinfection/burden_hiv_coinfection/en/.

7. Maia-Elkhoury AN, Alvez WA, Sousa-Gomes ML, et al. Visceral leishmaniasis in Brazil: trends and challenges. Cad Saude Publica 2008;24(12):2941-7.

8. Harhay MO, Olliaro PL, Costa DL, et al. Urban parasitology: visceral leishmaniasis in Brazil. Trends Parasitol 2011;27(9):403-9.

9. Registraron el primer caso de Leishmaniosis visceral en la provincia. Reporte Epidemiológico de Córdoba 2015;(1622):2. [Acceso: 1 de noviembre de 2016]. Disponible en: http: / / www.reporteepidemiologico.com/wp-content / uploads / 2015/07/REC-1622.pdf.

10. Primer caso autóctono de leishmaniosis en la provincia. Reporte Epidemiológico de Córdoba 2014;(1469):2-3. [Acceso: 1 de noviembre de 2016]. Disponible en: http: / / www.reporteepidemiologico.com/wp-content / uploads/2014/10/REC-1469.pdf.

11. Salomón O, Sinagra A, Nevot M, et al. First visceral leishmaniasis focus in Argentina. Mem Inst Oswaldo Cruz 2008;103(1):109-11.

12. Gould IT, Perner MS, Santini MS, et al. Leishmaniasis visceral en la Argentina. Notificación y situación vectorial (2006-2012). Medicina (B. Aires) 2013;73(2):104-10.

13. Grandoni L. Epidemiological surveillance of leishmaniasis in the European Union:operational and research challenges. Euro Surveill 2013;18(30):20539.

14. Harms-Zwingerberger G, Bienzle U. Leishmaniasis in Germany. Dtsch Arztebl 2007;104(45):3108-13.

15. Bogdan C, Schönian G, Bañuls AL, et al. Visceral leishmaniasis in a German child who had never entered a known endemic area: case report and review of the literature. Clin Infect Dis 2001;32(2):302-6. 